\title{
TERRITÓRIO E MULTITERRITORIALIDADE: UM DEBATE '
}

\author{
ROGÉRIO HAESBAERT \\ Universidade Federal Fluminense
}

Este trabalho está ligado ao prosseguimento de diversos trabalhos anteriores sobre o conceito de território e sua derivação direta, a territorialidade, e que culminaram com a proposta da noção de "multiterritorialidade" (HAESBAERT, 1997, 2001a, 2002a, 2004a). Trata-se de um debate sobre o desdobramento desta noção a partir de sua vinculação, em uma perspectiva mais sistematizada, com a concepção de "múltiplos territórios" e as diversas abordagens daquilo que se denomina territorialidade.

A multiterritorialidade, como já enfatizamos anteriormente (HAESBAERT, 2004a), aparece como uma alternativa conceitual dentro de um processo denominado por muitos como "desterritorialização". Muito mais do que perdendo ou destruindo nossos territórios, ou melhor, nossos processos de territorialização (para enfatizar a ação, a dinâmica), estamos na maior parte das vezes vivenciando a intensificação e complexificação de um processo de (re)territorialização muito mais múltiplo, "multiterritorial".

Foi nesse sentido que reconhecemos a desterritorialização como "mito" (HAESBAERT, 1994, 2001b, 2004a). Não no sentido de que simplesmente "não exista" desterritorialização, mas de que se trata de um processo indissociavelmente ligado à sua contraface, os movimentos de (re)territorialização. Como já afirmavam em seu "primeiro teorema" da desterritorialização os autores clássicos nesta temática, Deleuze e Guattari (ainda que numa conotação filosófica muito ampla):

\footnotetext{
'. Uma primeira versão deste artigo, intitulada "Dos múltiplos territórios à multiterritorialidade" foi apresentada no I Seminário Nacional sobre Múltiplas Territorialidades, promovido pelo Programa de Pós-Graduação em Geografia da UFRGS, Curso de Geografia da ULBRA e AGB-Porto Alegre, em 23 de setembro de 2004.
} 
Jamais nos desterritorializamos sozinhos, mas no mínimo com dois termos (...). E cada um dos dois termos se reterritorializa sobre o outro. De forma que não se deve confundir a reterritorialização com o retorno a uma territorialidade primitiva ou mais antiga: ela implica necessariamente um conjunto de artifícios pelos quais um elemento, ele mesmo desterritorializado, serve de territorialidade nova ao outro que também perdeu a sua. (DELEUZE E GUATTARI, 1996[1980]:40-41)

Geograficamente falando, não há desterritorialização sem reterritorialização pelo simples fato de que o homem é um "animal territorial" (ou "territorializador", como afirmou o sociólogo Yves Barel). O que existe, de fato, é um movimento complexo de territorialização, que inclui a vivência concomitante de diversos territórios - configurando uma multiterritorialidade, ou mesmo a construção de uma territorialização no e pelo movimento (HAESBAERT, 2004a). Por outro lado, é na dimensão mais propriamente social da desterritorialização, tão pouco enfatizada, que o termo teria melhor aplicação, pois quem de fato perde o "controle" e/ou a "segurança" sobre/em seus territórios são os mais destituídos, aqueles que se encontram mais "desterritorializados" ou, em termos mais rigorosos, mais precariamente territorializados.

Assim, afirmamos que, especialmente para os mais privilegiados, ditos por muitos "desterritorializados", "mais do que a desterritorialização desenraizadora, manifesta-se um processo de reterritorialização espacialmente descontínuo e extremamente complexo". (HAESBAERT, 1994:214) Estes processos de (multi)territorialização precisam ser melhor compreendidos, especialmente pelo potencial de perspectivas políticas inovadoras que eles exigem ou implicam.

\section{Território(s) e Territorialidade(s)}

Para falar em multiterritorialidade precisamos, em primeiro lugar, esclarecer o que entendemos por território e por territorialidade. Desde a origem, o território nasce com uma dupla conotação, material e simbólica, pois etimologicamente aparece tão próximo de terra-territorium quanto de terreoterritor (terror, aterrorizar), ou seja, tem a ver com dominação (jurídico-política) da terra e com a inspiração do terror, do medo - especialmente para aqueles que, com esta dominação, ficam alijados da terra, ou no "territorium" são impedidos de entrar. Ao mesmo tempo, por outro lado, podemos dizer que, para aqueles que têm o privilégio de plenamente usufrui-lo, o território pode inspirar a identificação (positiva) e a efetiva "apropriação".

Território, assim, em qualquer acepção, tem a ver com poder, mas não apenas ao tradicional "poder político". Ele diz respeito tanto ao poder no sentido 
mais explícito, de dominação, quanto ao poder no sentido mais implícito ou simbólico, de apropriação. Lefebvre distingue apropriação de dominação ("possessão", "propriedade"), o primeiro sendo um processo muito mais simbólico, carregado das marcas do "vivido", do valor de uso, o segundo mais concreto, funcional e vinculado ao valor de troca. Segundo o autor:

O uso reaparece em acentuado conflito com a troca no espaço, pois ele implica "apropriação" e não "propriedade". Ora, a própria apropriação implica tempo e tempos, um ritmo ou ritmos, símbolos e uma prática. Tanto mais o espaço é funcionalizado, tanto mais ele é dominado pelos "agentes" que o manipulam tornando-o unifuncional, menos ele se presta à apropriação. Por quê? Porque ele se coloca fora do tempo vivido, aquele dos usuários, tempo diverso e complexo. (Lefebvre, 1986:411412 , grifo do autor)

Como decorrência desse raciocínio, é interessante observar que, enquanto "espaço-tempo vivido", o território é sempre múltiplo, "diverso e complexo", ao contrário do território "unifuncional" proposto e reproduzido pela lógica capitalista hegemônica, especialmente através da figura do Estado territorial moderno, defensor de uma lógica territorial padrão que, ao contrário de outras formas de ordenação territorial (como a do espaço feudal típico), não admite multiplicidade/ sobreposição de jurisdições e/ou de territorialidades.

Podemos então afirmar que o território, imerso em relações de dominação e/ou de apropriação sociedade-espaço, "desdobra-se ao longo de um continuum que vai da dominação político-econômica mais 'concreta' e 'funcional' à apropriação mais subjetiva e/ou 'cultural-simbólica'”. (Haesbaert, 2004a:95-96) Segundo Lefebvre, dominação e apropriação deveriam caminhar juntas, ou melhor, esta última deveria prevalecer sobre a primeira, mas a dinâmica de acumulação capitalista fez com que a primeira sobrepujasse quase completamente a segunda, sufocando as possibilidades de uma efetiva "reapropriação" dos espaços, dominados pelo aparato estatal-empresarial e/ou completamente transformados, pelo valor contábil, em mercadoria.

Embora Lefebvre se refira sempre a espaço, e não a território, é fácil perceber que não se trata de espaço num sentido genérico e abstrato, muito menos de um espaço natural-concreto. Trata-se, isto sim, de um espaço-processo, um espaço socialmente construído. Diferentemente de autores como Raffestin (1993[1980]), para quem o espaço (físico-natural) é uma espécie de "matériaprima" para os processos de territorialização, como se o espaço antecedesse a construção do território, para Lefebvre o espaço, em sua tríplice constituição (enquanto espaço concebido, percebido e vivido), é sempre socialmente produzido. De certo modo, o que diferencia a produção do espaço lefebvreana das dinâmicas 
de territorialização aqui enfocadas é uma simples questão de foco, centralizado mais, aqui, nas relações de poder que constituem aquele espaço.

Se o espaço social aparece de maneira difusa por toda a sociedade e pode, assim, ser trabalhado de forma genérica, o território e as dinâmicas de desterritorialização (sempre hifenizada) devem ser distinguidos através dos sujeitos que efetivamente exercem poder, que de fato controlam esse(s) espaço(s) e, conseqüentemente, os processos sociais que o(s) compõe(m). Assim, o ponto crucial a ser enfatizado é aquele que se refere às relações sociais enquanto relações de poder - e como todas elas são, de algum modo, numa perspectiva foucaultiana, relações de poder, este deve ser qualificado, pois, dependendo da perspectiva teórica, pode compreender desde o "anti-poder" da violência ${ }^{2}$ até as formas mais sutis do poder simbólico.

Enquanto continuum dentro de um processo de dominação e/ou apropriação, o território e a territorialização devem ser trabalhados na multiplicidade de suas manifestações - que é também e, sobretudo, multiplicidade de poderes, neles incorporados através dos múltiplos sujeitos envolvidos (tanto no sentido de quem sujeita quanto de quem é sujeitado, tanto no sentido das lutas hegemônicas quanto das lutas de resistência - pois poder sem resistência, por mínima que seja, não existe). Assim, devemos primeiramente distinguir os territórios de acordo com aqueles que os constróem, sejam eles indivíduos, grupos sociais/culturais, o Estado, empresas, instituições como a Igreja etc. Os objetivos do controle social através de sua territorialização variam conforme a sociedade ou cultura, o grupo e, muitas vezes, com o próprio indivíduo (no caso da diferença de gênero, por exemplo). Controla-se uma "área geográfica", ou seja, cria-se o "território", visando "atingir/afetar, influenciar ou controlar pessoas, fenômenos e relacionamentos" (SACK, 1986:6).

A territorialidade, além de incorporar uma dimensão mais estritamente política, diz respeito também às relações econômicas e culturais, pois está "intimamente ligada ao modo como as pessoas utilizam a terra, como elas próprias se organizam no espaço e como elas dão significado ao lugar”. Sack afirma também:

A territorialidade, como um componente do poder, não é apenas um meio para criar e manter a ordem, mas é uma estratégia para criar emanter grande parte do contexto geográfico através do qual nós experimentamos o mundo e o dotamos de significado. (1986:219)

\footnotetext{
${ }^{2}$. Enquanto autores como Castoriadis propõem uma noção muito ampla de poder, envolvendo toda instituição da sociedade, distinguindo-o da "política" enquanto "questionamento explícito da " instituição estabelecida da sociedade" (1992:135), outros, como Hannah Arendt, restringem o poder "ao poder "legítimo", socialmente reconhecido, o que exclui a violência - é justamente "a perda de poder", diz ela, que "traz a tentação de substitui-lo pela violência" (Arendt, 2004:131).
} 
Portanto, todo território é, ao mesmo tempo e obrigatoriamente, em diferentes combinações, funcional e simbólico, pois as relações de poder têm no espaço um componente indissociável tanto na realização de "funções" quanto na produção de "significados". O território é "funcional" a começar pelo seu papel enquanto recurso, desde sua relação com os chamados "recursos naturais" "matérias-primas" que variam em importância de acordo com o(s) modelo(s) de sociedade(s) vigente(s) - como é o caso do petróleo no atual modelo energético dominante.

Para Raffestin, "um recurso não é uma coisa", a matéria em si, ele "é uma relação cuja conquista faz emergir propriedades necessárias à satisfação de necessidades". (1993:8) Como "meio para atingir um fim” (p. 225), não é uma relação estável, pois surge e desaparece na história das técnicas e da conseqüente produção de necessidades humanas. Milton Santos, inspirado em Jean Gottman, propõe distinguir o território como recurso, prerrogativa dos "atores hegemônicos", e o território como abrigo, dos "atores hegemonizados" (Santos et al., 2000:12). Se recurso é "um meio para obter um fim" (a acumulação e o lucro, para o capitalista, que pode abstrair-se da identificação com o espaço em que estes são realizados), para os "hegemonizados" o território, podemos dizer, seria "um fim em si mesmo"3 - para eles, assim, "perder seu território é", efetivamente, em mais de um sentido, "desaparecer", como propuseram Bonnemaison e Cambrèzy (1996).

Para muitos "hegemonizados" ou, como preferimos, subalternizados, o território adquire muitas vezes tamanha força que combina com igual intensidade funcionalidade e identidade. O território, neste caso, como defendem Bonnemaison e Cambrèzy (1996), "não diz respeito apenas à função ou ao ter, mas ao ser". É interessante como estas dimensões aparecem geminadas, sem nenhuma lógica a priori para indicar a preponderância de uma sobre a outra: muitas vezes, por exemplo, é entre aqueles que estão mais destituídos de seus recursos materiais que aparecem formas as mais vigorosas de apego a identidades territoriais ou "territorialismos".

Assim, poderíamos falar em dois grandes "tipos ideais" ou referências "extremas" frente às quais podemos investigar o território: um, mais funcional, priorizado na maior parte das abordagens, e outro, mais simbólico, que vem se impondo em importância nos últimos tempos. Enquanto "tipos ideais" eles nunca se manifestam em estado puro, ou seja, todo território "funcional" tem sempre alguma carga simbólica, por menos expressiva que seja, e todo território "simbólico" tem sempre algum caráter funcional, por mais reduzido que pareça. Num esquema genérico dos extremos deste já aludido continuum entre funcionalidade e simbolismo, podemos caracterizá-los da seguinte forma:

\footnotetext{
3. Agradecemos aqui as sugestões de Carlos Walter Porto Gonçalves.
} 
Território de dominância "funcional"

Processos de Dominação

"Territórios da desigualdade"

Território "sem territorialidade"

(empíricamente impossível)

Princípio da exclusividade

(no seu extremo: unifuncionalidade)

Território como recurso, valor de troca (controle físico, produção)
Território de dominância "simbólica"

Processos de Apropriação (Lefebvre)

"Territórios da diferença"

Territorialidade "sem território" (ex.: "Terra Prometida" dos judeus)

Princípio da multiplicidade (?) (no seu extremo: múltiplas identidades)

Território como símbolo, valor simbólico ("abrigo", "lar", segurança afetiva)

Embora a princípio pareça caber ao geógrafo manter sempre "os pés no chão" e enfatizar a dimensão material do território, a realidade contemporânea, dominada pelo mundo das imagens e das representações, acabou incorporando com certa ênfase no próprio âmbito das proposições geográficas uma visão "mais idealista" de território.

Para os geógrafos Bonnemaison e Cambrèzy (1996), por exemplo, vivemos hoje sob uma "lógica culturalista" ou "pós-moderna" de base identitária e reticular que se impõe sobre a lógica funcional e zonal (estatal) moderna. Por isso, "o território é primeiro um valor", estabelecendo-se claramente "uma relação forte, ou mesmo uma relação espiritual" com nossos espaços de vida. Numa distinção bastante questionável, o próprio "território cultural" precederia os territórios "político" e "econômico". (p. 10)

Na verdade, como fica mais nítido no seu grande trabalho empírico sobre a ilha de Tanna, no arquipélago de Vanuatu (Bonnemaison, 1997), trata-se mais de uma territorialidade - ou mesmo, em suas palavras, de uma "ideologia do território" - do que do território em sentido estrito. Cabe aqui, então, distinguirmos território e territorialidade - especialmente para reconhecermos que esta, independente ou não da efetivação de um território, tem papel cada vez mais relevante.

Segundo o próprio Bonnemaison, os habitantes de Tuva não "possuem" o território, mas se identificam com ele. Todos os conflitos, antigos ou recentes, são moldados por uma espécie de "ideologia do território" que remonta aos mitos sobre a criação do povo local. Embora em bases muito distintas e num jogo de influências sociais muito diverso das sociedades tradicionais, teríamos hoje um certo retorno às "ideologias territorialistas" que, em pleno mundo globalizado,

\footnotetext{
${ }^{4}$. É necessário lembrar que Bonnemaison (1997) inspirou-se aqui em sua tese sobre a sociedade da ilha de Tanna, bem pouco "pós-moderna", onde o território ("cultural") não é um produto dessa sociedade, mas uma entidade que a precede e a funda, os habitantes locais auto-definindo-se como man-ples, "homens-lugares". (p. 77)
} 
manifestam-se com crescente importância, a territorialidade, num sentido simbólico, impondo-se como argumento para a construção efetiva do território ou o território tornando-se, provavelmente, como afirmam Bonnemaison e Cambrèzy (1996:14), o mais eficaz de todos os construtores de identidade.

No jogo contemporâneo dos processos de destruição e reconstrução territorial fica muito claro o ir e vir entre territórios mais impregnados de um sentido funcional, de controle físico de processos, e aqueles onde a dimensão simbólica - a territorialidade, para alguns - adquire um papel fundamental. Aqui é importante aprofundar o debate sobre os vínculos e as possíveis distinções entre as noções de território e de territorialidade.

Alguns autores, numa visão mais estreita, reduzem a territorialidade à dimensão simbólico-cultural do território, especialmente no que tange aos processos de identificação territorial. Na maioria das vezes, porém, eles não fazem esta distinção, a territorialidade sendo concebida abstratamente, numa perspectiva mais epistemológica, como "aquilo que faz de qualquer território um território" (Souza, 1995:99), ou seja, as propriedades gerais reconhecidamente necessárias à existência do território - que variam, é claro, de acordo com o conceito de território que estivermos partilhando.

A territorialidade, no nosso ponto de vista, não é apenas "algo abstrato", num sentido que muitas vezes se reduz ao caráter de abstração analítica, epistemológica. Ela é também uma dimensão imaterial, no sentido ontológico de que, enquanto "imagem" ou símbolo de um território, existe e pode inserir-se eficazmente como uma estratégia político-cultural, mesmo que o território ao qual se refira não esteja concretamente manifestado - como no conhecido exemplo da "Terra Prometida" dos judeus, territorialidade que os acompanhou e impulsionou através dos tempos, ainda que não houvesse, concretamente, uma construção territorial correspondente.

Realizando uma revisão teórica sobre as diversas formas com que a concepção de territorialidade foi proposta, podemos sintetizar através do seguinte elenco de posições:

1) Territorialidade num enfoque mais epistemológico:

"abstração", condição genérica (teórica) para a existência do território (dependendo, assim, do conceito de território proposto)

2) Territorialidade num sentido mais ontológico:

a. Como materialidade (ex. controle físico do acesso através do espaço material, como indica Robert Sack)

b. Como imaterialidade (ex. controle simbólico, através de uma identidade territorial ou "comunidade territorial imaginada")

c. Como "espaço vivido" (frente aos espaços - neste caso, territórios, formais-institucionais), conjugando materialidade e imaterialidade. 
Como essas concepções devem estar sempre associadas a concepções de território correspondentes, é igualmente relevante "mapear" as distintas possibilidades de se trabalhar com a relação entre território e territorialidade, que se estende desde a indistinção até a completa separação entre eles. Agrupando estas leituras teríamos desde a territorialidade como uma concepção mais ampla do que território até a territorialidade como algo mais restrito, uma simples "dimensão" do território, passando pela abordagem diferenciadora, que separa e distingue claramente territorialidade e território. Daí:

a) Territorialidade como concepção mais ampla que território, que o engloba (a todo território corresponderia uma territorialidade, mas nem toda territorialidade teria, necessariamente, um território), territorialidade tanto como uma propriedade de territórios efetivamente construídos quanto como "condição" (teórica) para a sua existência (neste caso, reúnem-se as concepções 1 e 2 acima aludidas).

b) Territorialidade praticamente como sinônimo de território: a territorialidade como qualidade inerente à existência, efetiva, do território, condição de sua existência.

c) Territorialidade como concepção claramente distinta de território, em dois sentidos:

1.

territorialidade como domínio da imaterialidade, como concepção distinta de território, necessariamente material, concreto; a territorialidade definida na conjugação entre as concepções 1 e 2b, acima, ou seja, enquanto "abstração" analítica e enquanto dimensão imaterial ou identidade territorial.

2. territorialidade como domínio do "vivido" (concepção 2c) ou do não institucionalizado, frente ao território como espaço formal institucionalizado (implicando assim uma visão mais estrita de território, a partir de sua dimensão jurídico-política, formal)

d) Territorialidade como uma das dimensões do território, a dimensão simbólica (ou a "identidade territorial"), conforme utilizado algumas vezes no âmbito da Antropologia (neste caso a territorialidade seria tratada exclusivamente no sentido $2 \mathrm{~b}$, acima identificado). 
Assim, quando falamos em "territorialidade sem território" devemos tomar cuidado para esclarecer a que concepção de territorialidade ou a que relação entre território e territorialidade estamos nos referindo. Optamos aqui por tratar a territorialidade num sentido mais amplo do que território (relação 1), mas sempre com o cuidado de identificar, a cada momento, se estamos nos referindo à territorialidade como condição genérica para a existência de um território, tenha ele existência efetiva ou não (concepção 1), ou se estamos nos reportando à dimensão simbólica (concepção $2 b$ ) ou "vivida" do território (concepção 2c).

$\mathrm{O}$ que parece diferenciar nossa definição de território em relação a outras disciplinas é que não caracterizamos, nunca, território apenas pela sua dimensão simbólica - ao contrário da territorialidade, ele sempre envolve uma dimensão material-concreta. Assim, distinguimos duas dimensões principais do território, uma mais funcional e outra mais simbólica. Por isso, no quadro em que propusemos "território de dominância funcional" e "território de dominância simbólica", identificamos como possibilidade, num extremo (pois o esquema deve ser visto dentro de um continuum), a territorialidade "sem território", embora, no outro extremo, um território "sem territorialidade" seja empírica - e teoricamente inconcebível, dentro da concepção aqui proposta de que pode existir territorialidade sem território, mas não o contrário.

Envolvendo sempre relações de poder, é evidente que nossa concepção de território também inclui o poder no seu sentido simbólico (tal como proposto por Bourdieu, 1989). É justamente por fazer uma separação demasiado rígida entre território a partir de relações de poder num sentido mais concreto, "funcional", e território a partir de relações de poder mais simbólico que muitos ignoram a riqueza das múltiplas territorialidades em que estamos mergulhados. Propusemos assim definir território:

(...) a partir da concepção de espaço como um híbrido - híbrido entre sociedade e natureza, entre política, economia e cultura, e entre materialidade e "idealidade", numa complexa interação tempo-espaço, como nos induzem a pensar geógrafos como Jean Gottman e Milton Santos, na indissociação entre movimento e (relativa) estabilidade recebam estes os nomes de fixos e fluxos, circulação e "iconografias" [na acepção de Jean Gottman], ou o que melhor nos aprouver. (...) o território pode ser concebido a partir da imbricação de múltiplas relações de poder, do poder mais material das relações econômicopolíticas ao poder mais simbólico das relações de ordem mais estritamente cultural. (Haesbaert, 2004a:79)

Na verdade, hoje, mais do que nunca na história do capitalismo, a "sociedade do espetáculo" (na famosa expressão cunhada por Guy Débord) instituiu o amálgama, também no interior da "funcionalidade" capitalista, dos processos culturais de identificação e (re)criação de identidades. Compramos um produto muitas vezes 
mais pela sua imagem (valor simbólico) do que pela sua "função" (material). O "marketing" em torno destas imagens criadas sobre os objetos ampliou-se de tal forma que o próprio espaço geográfico, enquanto paisagem, é também transformado em mercadoria e vendido, como ocorre no "mercado de cidades" (e de regiões, deveríamos acrescentar) global. O "território simbólico" invade e refaz as "funções" num caráter complexo e indissociável em relação à funcionalidade dos territórios, ou seja, a dominação lefebvriana torna-se, mais do que nunca, também, simbólica - um simbólico, porém, que não advém do "espaço vivido" da maioria, mas da reconstrução identitária em função dos interesses dos atores hegemônicos.

Mais importante, portanto, do que esta caracterização problemática, porque genérica e aparentemente dicotômica, é perceber a historicidade do território, sua variação conforme o contexto histórico e geográfico - inclusive, como já ressaltamos, dentro das diversas fases do capitalismo. Os objetivos dos processos de territorialização, ou seja, de dominação e/ou de apropriação do espaço, variam muito ao longo do tempo e dos espaços. Assim, grande parte das sociedades tradicionais conjugava a construção material ("funcional") do território como abrigo e base de "recursos" com uma profunda identificação que recheava o espaço de referentes simbólicos fundamentais à manutenção de sua cultura. Já na sociedade "disciplinar" moderna (até o século XIX, pelo menos) dominava a funcionalidade de um "enclausuramento disciplinar" individualizante através do espaço - não dissociada, é claro, da construção das identidades-suporte da modernidade, a do indivíduo e a da nação (ou da "nação[enquanto]-Estado").

Mais recentemente, nas sociedades ditas "de controle" ou, para nós, "de segurança" (e, para outros, num outro sentido, "pós-modernas"), vigora o controle e/ou a contenção da mobilidade, dos fluxos (redes) e, conseqüentemente, das conexões - o território passa então, gradativamente, de um território mais "zonal" ou de controle de áreas (lógica típica do Estado-nação) para um "território-rede" ou de controle de redes (lógica típica das grandes empresas). Aí, o movimento ou a mobilidade passa a ser um elemento fundamental na construção do território.

Podemos, simplificadamente, falar em quatro grandes "fins" ou objetivos da territorialização, que podem ser acumulados e/ou distintamente valorizados ao longo do tempo:

- abrigo físico, fonte de recursos materiais e/ou meio de produção;

- identificação ou simbolização de grupos através de referentes espaciais (a começar pela própria construção de fronteiras);

- controle e/ou disciplinarização através do espaço (fortalecimento da idéia de indivíduo através de espaços também individualizados, no caso do mundo moderno);

- construção e controle de conexões e redes (fluxos, principalmente fluxos de pessoas, mercadorias e informações).

É importante que ressaltemos agora, então, dentro dessa multiplicidade territorial em que estamos mergulhados, quais os traços fundamentais que 
distinguem a atual fase des-reterritorializadora de caráter dito mais flexível do capitalismo e da modernidade (para alguns "pós-modernidade", para outros "modernidade radicalizada" [Giddens, 1990] ou "líquida" [Bauman, 2001]). Entendemos que uma marca fundamental é, ao lado da existência de múltiplos tipos de território, a experiência cada vez mais intensa daquilo que denominamos multiterritorialidade.

\section{Múltiplos territórios}

Inicialmente é necessário distinguir aquilo que denominamos "múltiplos territórios" e "multiterritorialidade" - a multiplicidade de territórios como uma condição sine qua non, necessária mas não suficiente, para a manifestação da multiterritorialidade. Rompendo com o dualismo entre fixidez e mobilidade, território e rede, propusemos uma primeira distinção, muito importante na constituição dos "múltiplos territórios" do capitalismo, entre territórios-zona, mais tradicionais, e territórios-rede, mais envolvidos pela fluidez e a mobilidade. Mais do que suas formas, entretanto, importa o tipo de poder e os sujeitos neles envolvidos.

Poderíamos mesmo, generalizando ao extremo, afirmar que o capitalismo se funda, geograficamente, sob dois grandes "paradigmas" territoriais - um mais típico da lógica estatal "tradicional", preocupada com o controle de fluxos pelo controle de áreas, quase sempre contínuas e de fronteiras claramente definidas; outro mais relacionado à lógica empresarial, também controladora de fluxos, porém prioritariamente através de sua "canalização" em dutos e nódulos de conexão (as redes), de alcance, em última instância, global. Arrighi (1996), de forma geograficamente questionável, distinguiu dois "modos opostos de governo ou de lógica do poder" em relação à dinâmica entre capital (ou espaço econômico) e a "organização relativamente estável do espaço político", duas estratégias geopolíticas (e geo-econômicas) que ele denomina de "capitalismo" e "territorialismo":

Os governantes territorialistas identificam o poder com a extensão e a densidade populacional de seus domínios, concebendo a riqueza/o capital como um meio ou um subproduto da busca de expansão territorial. Os governantes capitalistas, ao contrário, identificam o poder com a extensão de seu controle sobre os recursos escassos e consideram as aquisições territoriais um meio e um subproduto da acumulação de capital. (p. 33)

\footnotetext{
5. "Historicamente, o capitalismo, como sistema mundial de acumulação e governo, desenvolveuse simultaneamente nos dois espaços. No espaço-de-lugares (...) ele triunfou ao se identificar com certos Estados. No espaço-de-fluxos, em contraste, triunfou por não se identificar com nenhum Estado em particular, mas por construir organizações empresariais não territoriais que abrangiam o mundo inteiro". (p. 84)
} 
Essas duas lógicas de poder dentro do sistema mundial de acumulação aparecem também associadas a dinâmicas espaciais distintas - uma, o "capitalismo" em sentido estrito, seria marcada sobretudo pelo "espaço dos fluxos" das grandes organizações empresariais, enquanto a outra, o "territorialismo", marcado pela lógica estatal, seria também o domínio do "espaço dos lugares"s.

O autor destaca, contudo, que são duas lógicas não-excludentes, pois historicamente funcionariam em conjunto, "relacionadas entre si num dado contexto espaço-temporal". (p. 34) Desde o exemplo dado por Arrighi como "protótipo do Estado capitalista", a Veneza do final da Idade Média e outras cidades-Estado do norte italiano, percebe-se com clareza a constituição de "territórios-rede" onde o controle era exercido tanto sobre o que o autor denomina de "enclaves anômalos" (as cidades-Estados), loci principais das poderosas oligarquias mercantis, quanto sobre suas redes de atuação, que envolviam o domínio direto ou indireto (pelo comércio) sobre outras áreas (territórios-zona) e o domínio das rotas marítimas que permitiam a sua interconexão.

Bourdin (2001), comentando Balligand e Maquart, afirma:

(...) sempre houve territórios descontínuos, os dos comerciantes e seus balcões, os das peregrinações e de suas igrejas de romaria, "territórios-rede" de que o Império de Veneza oferece uma perfeita ilustração. Hoje, este tipo de território domina, dando um outro significado aos recortes tradicionais, sobretudo políticos. (p. 167)

Assim, dentro da diversidade territorial do nosso tempo devemos levar em conta, em primeiro lugar, essa distinção crescente entre uma lógica territorial zonal e uma lógica territorial reticular ${ }^{6}$. Elas se interpenetram, se mesclam, de tal modo que a efetiva hegemonia dos territórios-zona estatais que marcaram a grande colcha de retalhos política, pretensamente uniterritorial (no sentido de só admitir a forma estatal de controle político-territorial) do mundo moderno, vê-se obrigada, hoje, a conviver com novos circuitos de poder que desenham complexas territorialidades, em geral na forma de territórios-rede, como é o caso das territorialidades do narcotráfico e do terrorismo globalizado.

Isso não significa, entretanto, que uma lógica reticular se imponha inexoravelmente dentro de uma "sociedade em rede", e que defendamos, de forma simples, a preponderância desta forma de organização territorial. A lógica zonal não só não desapareceu como é um constituinte indissociável das práticas sociais, na medida em que sempre existirão relações sociais (de poder) que irão requisitar

${ }^{6}$. Para uma discussão mais aprofundada desta temática, bem como da noção de território-rede, ver o item 7.1 (Territórios, redes e territórios-rede) em Haesbaert, 2004a, pp. 279-311.

7. Ainda que esta "legislação" seja de exceção, como discutido por Agamben (2002), e esteja inserida em processos de uma renovada "reclusão" ou, num termo provavelmente mais consistente, "contenção" territorial (Haesbaert, 2004b), por referir-se mais a uma lógica territorial reticular ("contenção de fluxos") do que zonal. 
o domínio de espaços contínuos e delimitados onde se "legisle" em nome de todos os integrantes desses espaços/territórios ${ }^{7}$. As organizações em rede, como todos sabem, nunca preenchem o espaço social em seu conjunto, inserindo-se, portanto, "naturalmente", dentro de dinâmicas sociais excludentes. A defesa de um "espaço de todos" (ou o "espaço banal" de Milton Santos), de um território efetivamente a serviço de processos crescentes de democratização, não pode nunca se restringir apenas à modalidade de territórios-rede.

Dentro dessa complexa relação entre redes e áreas ou zonas como os dois elementos fundamentais constituintes do território (para Raffestin, duas das três "invariantes" territoriais - a terceira seriam os pólos ou nós, que no nosso ponto de vista são, juntamente com os "dutos" e/ou fluxos, constituintes indissociáveis das redes), devemos destacar a enorme variedade de tipos e níveis de controle e/ou contenção territorial. Se o território é moldado sempre dentro de relações de poder, em sentido lato, ele envolve sempre, também, no dizer de Robert Sack, o controle de uma área pelo controle da sua acessibilidade. Este controle, contudo, dependendo do tipo (mais funcional ou mais simbólico, por exemplo) e dos sujeitos que o promovem (a grande empresa, o Estado, grupos étnico-culturais, etc.), adquire níveis de intensidade os mais diversos. Assim, com base em discussões anteriores (Haesbaert, 2002b e 2004a), propomos identificar "múltiplos territórios" - ou melhor, "múltiplas territorializações", através das seguintes modalidades:

a)

Territorializações (para quem efetivamente exerce seu controle, espaços de "exclusão inclusiva", "territórios de exceção" dentro da ordem vigente) mais desterritorializantes, "desidentificadoras" ("espaços de indistinção") e destituidoras de cidadania (porque aí a exceção e a biologização da "vida nua" se tornam a regra [Agamben, 2002]), como os campos de refugiados e outros espaços através dos quais se tenta conter a massa de "excluídos" que Agamben define genericamente como "campos" (tendo no seu extremo o efetivo fechamento dos campos de concentração) $)^{8}$.

b) Territorializações mais fechadas, quase "uniterritoriais" no sentido de imporem a correspondência entre poder político e identidade cultural, ligadas ao fenômeno do territorialismo, como nos territórios defendidos por grupos étnicos que se pretendem culturalmente homogêneos, não admitindo uma pluralidade territorial de poderes e identidades.

8. Para Agamben, o "campo" é o "mais absoluto espaço biopolítico de poder que jamais tenha sido realizado, no qual o poder tem diante de si senão a pura vida nua, sem qualquer mediação". (2002) 
c) Territorializações político-funcionais mais tradicionais, como a do Estado-nação que, pelo menos quando referido mais ao território do que ao "sangue" (do contrário equivaleria ao caso anterior), mesmo admitindo certa pluralidade cultural (sob a bandeira de uma mesma "nação" enquanto "comunidade [territorialmente] imaginada" (Anderson, 1989), não admite a pluralidade de poderes.

d) Territorializações mais flexíveis, que admitem a sobreposição territorial, seja sucessiva (como nos territórios temporários ou espaços multifuncionais na área central das grandes cidades) ou simultaneamente (como na sobreposição "encaixada" de territorialidades político-administrativas relativamente autônomas).

e) Territorializações efetivamente múltiplas - uma "multiterritorialidade" em sentido estrito, construída por grupos que se territorializam na conexão flexível de territórios-rede multifuncionais, multi-gestionários e multi-identitários, como no caso de diásporas de migrantes.

Precisamos então, a partir daí, distinguir entre "múltiplos territórios" e "multiterritorialidade". O antropólogo colombiano Zambrano (2001), numa perspectiva semelhante, traz contribuições interessantes. Ele distingue entre "territórios plurais" e "pluralidade de territórios". Com base na complicada realidade sócio-política e cultural da Colômbia, Zambrano reconhece a multiplicidade de territórios através dos próprios movimentos sociais e das lutas travadas por diferentes grupos e instituições. Assim, afirma ele:

No âmbito político o pertencimento gera o sentido de domínio sobre um lugar, sentido que estimula o aparecimento de formas de autoridade e tributação sobre o espaço, configurando a real perspectiva territorial: percepções de atores diversos, geralmente alheios aos contornos territoriais locais (Estado, guerrilhas, ONGs etc.) que inserem suas visões, confrontando-se com as dos residentes (organização social, formas de parentesco, uso do espaço etc.) que devem lutar pela hegemonia de um modo particular de exercer legitimamente o domínio ou estabelecê-lo com as pautas de dominação intervenientes que lhes são alheias. A propriedade da

\footnotetext{
9. O autor parte de uma definição de território como "o espaço terrestre, real ou [?] imaginado, que um povo (etnia ou nação) ocupa ou utiliza de alguma maneira, sobre o qual gera sentido de pertencimento, que confronta com o de outros, e organiza de acordo com os padrões de diferenciação produtiva (riqueza econômica), social (origem de parentesco) e sexo/gênero (divisão sexual dos espaços) e [sobre o qual] exerce jurisdição". (Zambrano, 2001:29)
} 
terra como fundamento do território é deslocada pela noção de soberania que é ação de domínio sobre o espaço de pertencimento, real ou imaginado. Sem as amarras da propriedade, o territorial surge com mais nitidez enquanto espaço de relações políticas entre as distintas representações que legitimam as ações de domínio sobre ele (...). A jurisdição tem fronteiras difusas que não são físicas, isto $e ́$, são desterritorializadas, política e socialmente falando, razão pela qual o sentido de domínio se translada com os atores que deixam suas marcas nas localidades. Aparecem assim as jurisdições guerrilheiras, paramilitares, municipais, indígenas, afrocolombianas, ecológicas, judiciais, eclesiásticas etc., num mesmo lugar, configurando nele uma arena própria para a luta territorial. (p. 17, tradução livre)

Ainda que questionemos este caráter "desterritorializado" das jurisdições (cujo termo pode muitas vezes ser substituído por "territorialidades"), é evidente, na análise do autor, a multiplicidade de territórios - e também, num sentido mais amplo, territorialidades - que podem conviver num mesmo espaço, alimentando ou não as lutas pelo território. É o próprio Zambrano quem afirma, mais adiante, que o espaço pode ser concebido como "um cenário de pugna entre territorialidades, isto é, entre jurisdições, reais e imaginadas, que incidem sobre os territórios estruturados e habitados". Sugere então que "os territórios plurais são uma multiplicidade de espaços diversos, culturais, sociais e políticos, com conteúdos jurisdicionais em tensão, que produzem formas particulares de identidade territorial" (p. 18), um pouco como se todo território (formalmente instituído) implicasse o convívio de múltiplas territorialidades.

Distingue-se assim "pluralidade de territórios" e "territórios plurais", que, longe de uma "armadilha semântica", permite enfocar, segundo o autor, duas qualificações distintas:

A pluralidade de territórios indica sua multiplicidade: "a superfície terrestre como suporte está sujeita a um processo permanente de organização/diferenciação, processo central para a reprodução sistêmica. (...)" Os territórios plurais, além de conceberem a multiplicidade descrita anteriormente, concebem todo espaço terrestre ocupado por distintas representações sobre ele, que tendem a legitimar a jurisdição sobre os habitantes que nele residem, configurando a série de relações sociais entre as diferentes percepções de domínio. (....) Os territórios plurais permitem perceber, em cada unidade do múltiplo, a pluralidade de percepções territoriais estruturadas [a cotidianeidade dos habitantes], estruturando [processo de construção] e estruturantes [ex.: judiciais, eclesiásticas e algumas guerrilheiras, formadas pela 
progressiva ação dos movimentos sociais]. (p. 29-30)

Contendo a pluralidade de territórios, os territórios plurais se manifestariam pelo menos de duas formas (p. 31):

- multiplicidade de territórios: território plural como reunião de vários territórios (e territorialidades, poderíamos acrescentar);

- pluralidade de jurisdições: território plural por abranger diferentes jurisdições (incorporando-as parcialmente ou por sobreposição).

A pluralidade de territórios pode estar compreendida de duas formas nos "territórios plurais" (noção mais próxima de nossa concepção de multiterritorialidade) - uma, vista a partir do "território plural" como conjunto justaposto de diversos territórios compreendidos no seu interior, outra, a partir do "território plural" como conjunto superposto de vários territórios (ou territorialidades) cuja abrangência pode ir bem além dos seus limites.

É como se fossem duas perspectivas distintas: na primeira, o olhar vai mais dos limites do "território plural" para o seu interior, na segunda o olhar prioriza as relações deste território com aqueles que se encontram para além ou "acima" dele. Tanto num caso como no outro o convívio de múltiplas territorialidades implica sempre disputas. Como afirma Zambrano, "o território se conquista", sendo assim "luta social convertida em espaço". (2001:31) Trata-se, aí, de duas manifestações daquilo que desdobraremos no próximo item como "multiterritorialidade" - tanto pela justaposição (sucessão) quanto pela sobreposição (simultaneidade) territorial. Se o território é "luta social" enquanto "conquista pelo espaço", como indica Zambrano, ela envolve sempre, como já destacamos, jogos mais concretos, materiais-funcionais, e jogos mais simbólicos de poder.

\section{Multiterritorialidade}

Para entendermos a multiterritorialidade contemporânea é preciso remontar às suas "origens". Na verdade, especialmente levando em conta as concepções de território e de territórios múltiplos anteriormente discutidas, podemos afirmar que sempre vivemos uma multiterritorialidade:

(...) a existência do que estamos denominando multiterritorialidade, pelo menos no sentido de experimentar vários territórios [e/ou territorialidades] ao mesmo tempo e de, a partir dai, formular uma territorialização efetivamente múltipla, não é exatamente uma novidade, pelo simples fato de que, se o processo de territorialização parte do nível individual ou de pequenos grupos, toda relação social implica uma interação territorial, um entrecruzamento de diferentes territórios. Em 
certo sentido, teríamos vivido sempre uma "multiterritorialidade". (Haesbaert, 2004a:344)

Fica evidente, a partir daí, a necessidade de distinguir, inicialmente, multiterritorialidade num sentido amplo, ligada à propriedade genérica da multiplicidade territorial (que, por sua vez, faz eco à "multiplicidade" do espaço, no sentido enfatizado por Massey, 2004), e multiterritorialidade num sentido mais estrito, que envolve a experiência efetiva de múltiplos territórios e/ou territorialidades reconhecidas as distinções anteriormente apresentadas.

Um dos primeiros cientistas sociais a falar de multi-pertencimento territorial e multiterritorialidade foi o sociólogo francês Yves Barel. Ele parte de uma noção demasiado ampla e "sociologizante" de território, definido como o "não-social dentro do qual o social puro deve imergir para adquirir existência" (Barel, 1986:131), para afirmar que:

(...) o homem, por ser uma animal político e um animal social, é também um animal territorializador [poderia ter dito também "territorial", pois não há homem sem território, este como imanente ao caráter humano]. Diferentemente, talvez, de outras espécies animais, seu trabalho de territorialização apresenta, contudo, uma particularidade marcante: a relação entre o indivíduo ou o grupo humano e o território não é uma relação biunívoca. Isto significa que nada impede este indivíduo ou este grupo de produzir e de "habitar" mais de um território. (...) é raro que apenas um território seja suficiente para assumir corretamente todas as dimensões de uma vida individual ou de um grupo. $O$ indivíduo, por exemplo, vive ao mesmo tempo ao seu "nível", ao nível de sua família, de um grupo, de uma nação. Existe portanto multipertencimento territorial. (p. 135)

Trata-se, contudo, daquilo que podemos denominar multiterritorialiade em um sentido mais tradicional, resultante de uma sobreposição lógica de territórios, hierarquicamente articulados, "encaixados". Os exemplos citados por Barel, um pouco como na espacialidade diferencial de Yves Lacoste, comentada a seguir, deixam claro que se trata de uma multiterritorialidade pelo "encaixe" de territórios em diferentes dimensões ou escalas.

Assim, Barel dá como exemplo de "multiterritorialidade contemporânea" a política de emprego - exemplo coerente com sua ampla concepção de território. A luta contra o desemprego não pode mais ficar subordinada às iniciativas de caráter estatal-nacional, pois se trata de um fenômeno internacional ou mesmo, global. As políticas nacionais, assim, "se tornam políticas locais, freqüentemente ineficazes por causa de seu localismo”. (p. 137-138) 
Seria então a multiterritorialidade uma questão de escala ou, nos termos de Lacoste, uma questão de espacialidade diferencial? Neste sentido, é interessante que reflitamos um pouco sobre as relações entre multiterritorialidade e espacialidade diferencial.

Lacoste (1988) ressalta a diferença entre a espacialidade aldeã ou rural e a espacialidade urbana. Mesmo sem usar o termo, ele já antecipa a "compressão tempo-espaço" (Harvey, 1992), profundamente diferenciada conforme as "geometrias de poder" (Massey, 1993) em que estão situados os grupos sociais, ao afirmar que "nos dias de hoje, (...) tudo aquilo que está longe sobre a carta é bem perto por determinado meio de circulação. (...) Hoje, nós nos defrontamos com espaços completamente diferentes, caso sejamos pedestres ou automobilistas (ou, com mais razão ainda, se somarmos o avião)". Assim, na nossa vida cotidiana, referimo-nos, "mais ou menos confusamente, a representações do espaço de tamanhos extremamente não-semelhantes (...) ou, antes, a pedaços de representação espacial superpostos, em que as configurações são muito diferentes umas das outras".

Essa "multi-escalaridade" das práticas - e representações - socioespaciais implica a vivência de múltiplos "papéis" que "se inscrevem cada um em migalhas de espaço", descontínuo, multiescalar:

Vivemos, a partir do momento atual, numa espacialidade diferencial feita de uma multiplicidade de representações espaciais, de dimensões muito diversas, que correspondem a toda uma série de práticas e de idéias, mais ou menos dissociadas (...).(Lacoste, 1988:49)

O autor reconhece então as diferentes representações do espaço referidas à nossa mobilidade mais restrita, cotidiana (a nível de bairro, cidade, deslocamentos de fim de semana); as configurações espaciais não-coincidentes das redes das quais dependemos (redes administrativas, de comercialização, de influência urbana, financeiras); e as representações espaciais de mais ampla escala, veiculadas pela mídia e pelo turismo, e que freqüentemente abarcam o globo no seu conjunto. Assim:

O desenvolvimento desse processo de espacialidade diferencial se traduz por essa proliferação de representações espaciais, pela multiplicação das preocupações concernentes ao espaço (nem que seja por causa da multiplicação dos deslocamentos). Mas esse espaço do qual todo mundo fala, ao qual nos referimos todo tempo, é cada vez mais difícil de apreender globalmente para se perceber suas relações com uma política global. (Lacoste, 1988:50) 
A dificuldade em "apreender globalmente" nossa experiência espacial contemporânea, destacada por Lacoste, tem a ver com a descontinuidade dos espaços - e dos territórios, organizados muito mais em rede do que em termos de áreas. Provém daí um sério dilema político, a ser retomado em outro trabalho: como organizar movimentos políticos de resistência através de um espaço tão fragmentado e, em tese, multi-escalar e... desarticulado?

Se para Lacoste "as práticas sociais se tornaram mais ou menos confusamente multiescalares" (p. 48-49), muitos de nós, contudo, encarregam-se de desfazer a confusão deste novelo e, retomando seus fios, tecer sua própria rede, ou melhor, seu(s) próprio(s) território(s)-rede(s) - que implicam, sem dúvida, assim, a vivência de uma multiterritorialidade, pois todo território-rede resulta da conjugação, em uma escala diferente, de territórios-zona, descontínuos. Além disso, mais do que de superposição espacial, como enfatiza o autor, trata-se hoje, principalmente com o novo aparato tecnológico-informacional à nossa disposição, de uma multiterritorialidade não apenas por deslocamento físico como também por "conectividade virtual", a capacidade de interagirmos à distância, influenciando e, de alguma forma, integrando outros territórios.

Distinguimos então pelo menos duas grandes perspectivas de tratamento da multiterritorialidade:

(...) aquela que diz respeito a uma multiterritorialidade "moderna", zonal ou de territórios de redes, embrionária, e a que se refere à multiterritorialidade "pós-moderna", reticular ou de territórios-rede propriamente ditos, ou seja, a multiterritorialidade em sentido estrito. (Haesbaert, 2004a:348)

A multiterritorialidade contemporânea inclui assim uma mudança não apenas quantitativa - pela maior diversidade de territórios que se colocam ao nosso dispor (ou, pelo menos, das classes e grupos mais privilegiados) - mas também qualitativa, na medida em que temos hoje a possibilidade de combinar de uma forma inédita a intervenção e, de certa forma, a vivência, concomitante, de uma enorme gama de diferentes territórios e/ou territorialidades.

A chamada condição pós-moderna inclui assim uma multiterritorialidade:

(...) resultante do domínio de um novo tipo de território, o territóriorede em sentido estrito (...). Aqui, a perspectiva euclidiana de um espaçosuperficie contínuo praticamente sucumbe à descontinuidade, à fragmentação e à simultaneidade de territórios que não podemos mais distinguir claramente onde começam e onde terminam ou, ainda, onde irão "eclodir", pois formações rizomáticas também são possíveis. (...) (Haesbaert, 2004a:348) 
Esta flexibilidade territorial do mundo dito "pós-moderno", embora não seja uma marca universalmente difundida (longe disso), permite que alguns grupos, em geral os mais privilegiados, usufruam de uma multiplicidade inédita de territórios, seja no sentido da sua sobreposição num mesmo local, seja da sua conexão em rede por vários pontos do mundo. Aqui podemos lembrar a multiterritorialidade mais funcional da organização terrorista Al Qaeda, já analisada anteriormente (Haesbaert, 2002a), e a multiterritorialidade funcional e simbólica da elite ou da "burguesia" globalizada.

Ao contrário da "extraterritorialidade" dos globetrotters ou "turistas" globalizados de Bauman (1999), destacamos a multiterritorialidade da nova elite planetária. Partindo do pressuposto de que todo poder social é um poder sobre o espaço, os sociólogos Pinçon e Pinçon-Charlot (2000) afirmam que a "burguesia" (conceito polêmico) contemporânea se reproduz ao mesmo tempo pela proximidade residencial (em bairros e/ou condomínios seguros e plenos de amenidades) "território-zona" no seu sentido mais tradicional - e pela multiterritorialidade, ou seja, pelo usufruto de múltiplos territórios, reveladores de uma dupla inserção social, tanto no sentido de uma profunda memória familiar quanto de uma intensa vida mundana. Esta multiterritorialidade também seria visível através do caráter de "classe internacional", tanto no sentido da internacionalização da vida profissional ou de negócios quanto de lazer, via turismo internacional.

O sociólogo Ulrich Beck (1999) chega mesmo a forjar o termo "topoligamia" para se referir a este fenômeno de "casamento com diversos lugares", para ele muito difundido, mas que aqui enfatizamos como um fenômeno mais característico dos grupos mais privilegiados. Citando o caso de uma senhora que divide anualmente sua vida entre uma casa na Alemanha e outra no Quênia, ele constata que ela "tem uma vida topoligâmica, está afeiçoada a coisas que parecem excludentes, África e Tutzing. Topoligamia transnacional, estar casado com lugares que pertencem a mundos distintos: esta é a porta de entrada da globalidade da vida de cada um (...)". (p. 135) Num sentido mais amplo do que o nosso para multiterritorialidade, ele trabalha com processos de "pluri" ou "multilocalização", "a alternância e a escolha dos lugares" como "padrinhos da globalização". (p. 137)

É importante acrescentar a esta mobilidade física extremamente facilitada de que usufrui a classe hegemônica contemporânea, que podemos denominar, num sentido de mobilidade física, uma "multiterritorialidade sucessiva", a sua "mobilidade virtual" ou uma "multiterritorialidade simultânea".

Como diz Bauman, a maioria das pessoas "está em movimento mesmo se fisicamente parada" (1999:85). Para estas, o espaço enquanto distância parece importar muito pouco. Por outro lado, a acessibilidade geográfica ampliada de que dispõe a elite planetária não impede que ela tenha nạo só que se "proteger" em termos de espaço residencial como também de manter as conexões, físicas e/ 
ou informacionais, entre os múltiplos territórios que, combinados, conformam a sua multiterritorialidade.

Tal como afirmamos em trabalho anterior (Haesbaert, 2004a), dentro dessas novas articulações espaciais em rede surgem territórios-rede flexíveis onde o que importa é ter acesso, ou aos meios que possibilitem a maior mobilidade física dentro da(s) rede(s), ou aos pontos de conexão que permitam "jogar" com as múltiplas modalidades de territorialidade existentes, criando a partir daí uma nova (multi)territorialidade.

Trata-se assim de vivenciar essas múltiplas modalidades, de forma simultânea (no caso da mobilidade "virtual", por exemplo) ou sucessiva (no caso da mobilidade física), num mesmo conjunto que, no caso dos indivíduos ou de alguns grupos, pode favorecer mais uma vez, agora não mais na forma de territórioszona contínuos, um novo tipo de "experiência espacial integrada". Esta nova experiência, que é a experiência da multiterritorialidade em sentido estrito, inclui:

- uma dimensão tecnológico-informacional de crescente complexidade, em torno daquilo que podemos denominar uma reterritorialização via ciberespaço (e não uma desterritorialização, como defende Lévy, 1996, 1999), e que resulta na extrema valorização da maior densidade informacional extremamente seletiva de alguns pontos altamente estratégicos do espaço;

- como decorrência dessa nova base tecnológico-informacional, uma compressão espaço-tempo de múltiplos alcances ou "geometrias de poder" (com o fenômeno do alcance planetário instantâneo ou em "tempo real"), com contatos globais de alto grau de instabilidade e imprevisibilidade;

- uma dimensão cultural-simbólica cada vez mais importante dos processos de territorialização, com a identificação territorial ocorrendo muitas vezes no/ com o próprio movimento e, no seu extremo, referida à própria escala planetária como um todo (a "Terra-pátria" de Morin e Kern, 1995).

Nesse contexto:

A principal novidade é que hoje temos uma diversidade ou um conjunto de opções muito maior de territórios/territorialidades com os/as quais podemos "jogar", uma velocidade (ou facilidade, via Internet, por exemplo) muito maior (e mais múltipla) de acesso e trânsito por essas territorialidades - elas próprias muito mais instáveis e móveis - e, dependendo de nossa condição social, também muito mais opções para desfazer e refazer constantemente essa multiterritorialidade. (Haesbaert, 2004a:344)

O mais importante a destacar na nossa experiência multiterritorial contemporânea é o fato de que não se trata simplesmente, como já ressaltamos, da imbricação ou da justaposição de múltiplos territórios que, mesmo recombinados, 
mantêm sua individualidade numa espécie de "todo" como produto ou somatório de suas partes. A efetiva multiterritorialidade, hoje, seria uma experiência profundamente inovadora a partir da compressão espaço-temporal que permite

\section{(...) pela comunicação instantânea, contatar e mesmo agir [como no} caso de grandes empresários que praticamente "dirigem" suas fazendas ou firmas à distância, via Internet e outras modalidades informacionais] sobre territórios completamente distintos do nosso, sem a necessidade de mobilidade física. Trata-se de uma multiterritorialidade envolvida nos diferentes graus daquilo que poderíamos denominar como sendo a conectividade e/ou vulnerabilidade informacional (ou virtual) dos territórios. (Haesbaert, 2004a:345)

É importante distinguir aí, claramente, a dimensão mais propriamente material e a dimensão simbólica da multiterritorialidade. Assim como concebemos o território dentro de um contínuo do mais funcional ao mais simbólico (no extremo, uma territorialidade "sem território"), também a multiterritorialidade pode ter uma dimensão concreta mais incisiva, como no caso da tele-ação ou ação à distância, anteriormente aludida, e uma maior carga simbólica, como no caso da chamada "hibridação" de referências identitário-territoriais (Haesbaert, no prelo), num amálgama capaz de recriar, mesmo no hibridismo, processos de identificação e (re)construção territorial (a identificação com "lugares híbridos", multiidentitários).

A realização da multiterritorialidade contemporânea, é evidente, envolve como condições básicas a presença de uma grande multiplicidade de territórios e territorialidades (incluindo territórios/territorialidades mais "híbridos"), bem como sua articulação na forma, principalmente, de territórios-rede. Estes, como já vimos, são por definição, sempre, territórios múltiplos, na medida em que podem conjugar territórios-zona (manifestados numa escala espacialmente mais restrita) através de redes de conexão (numa escala mais ampla). A partir daí se desenham também diferenciações dentro da própria dinâmica de "multiterritorialização". Mesmo exigindo um desdobramento futuro, é necessário distinguir, por exemplo:

- os agentes que promovem a multiterritorialização e as profundas distinções em termos de objetivos, estratégias e escalas, sejam eles indivíduos, grupos, instituições, o Estado ou as empresas.

- o caráter mais simbólico ou mais funcional da multiterritorialidade - tal como no que se refere à definição de território, ela aparece ora com uma maior carga simbólica (como no caso das grandes diásporas de imigrantes), ora com maior carga funcional (como no caso das redes do megaterrorismo global); no primeiro caso é importante analisar também as múltiplas identidades territoriais 
(territorialidades num sentido cultural) nela envolvidas.

- os níveis de compressão espaço-tempo (e, conseqüentemente, de "teleação") nela incorporados, ou seja, as múltiplas "geometrias de poder" dessa compressão, bem como o sentido potencial ou efetivo de sua realização.

- o caráter contínuo ou descontínuo da multiterritorialidade, até que ponto ela ocorre pela justaposição (ou "encaixe"), num mésmo espaço, de múltiplos territórios (ou, por outro lado, pela vivência de "territórios múltiplos"), e até que ponto ela corresponde à conexão de múltiplos territórios, em rede (identificando então, tal como na distinção entre territórios-zona e territórios-rede, uma multiterritorialidade "zonal" mais "tradicional" ou em sentido lato, e uma multiterritorialidade "reticular" em sentido mais estrito).

- a combinação de "tempos espaciais" incorporada à multiterritorialidade - devendo-se discutir assim, também, de alguma forma, as implicações das múltiplas territorialidades acumuladas desigualmente ao longo do tempo (Santos, 1978) ${ }^{10}$ na construção da multiterritorialidade.

\section{4. (Não) concluindo: implicações políticas do conceito}

Numa breve (in)conclusão, apontando também para desdobramentos futuros, podemos afirmar que o mais importante neste debate diz respeito às implicações políticas do conceito de multiterritorialidade, suas repercussões em termos de intervenção na realidade concreta ou em termos estratégicos de poder. Como já afirmamos, é necessário distinguir, por exemplo, entre a multiterritorialidade potencial (a possibilidade de ela ser construída ou acionada) e a multiterritorialidade efetiva, real-izada:

As implicações políticas desta distinção são importantes, pois sabemos que a disponibilidade do "recurso" multiterritorial - ou a possibilidade de ativar ou de vivenciar concomitantemente múltiplos territórios - é estrategicamente muito relevante na atualidade e, em geral, encontrase acessivel apenas a uma minoria. Assim, enquanto uma elite globalizada tem a opção de escolher entre os territórios que melhor lhe aprouver, vivenciando efetivamente uma multiterritorialidade, outros, na base da pirâmide social, não têm sequer a opção do "primeiro"

\footnotetext{
${ }^{10}$. Milton Santos sugeriu a noção de tempo espacial para dar conta do "problema das superposições" tanto no tempo quanto no espaço, já que "cada variável hoje presente na caracterização de um espaço aparece com uma data de instalação diferente, pelo simples fato de que não foi difundida ao mesmo tempo". Assim, cada lugar seria "o resultado de ações multilaterais que se realizam em tempos desiguais sobre cada um e em todos os pontos da superfície terrestre”. (Santos, 1978:211)
} 
território, o território como abrigo, fundamento mínimo de sua reprodução física cotidiana. (Haesbaert, 2004a:360)

Pensar, como inúmeros autores nas Ciências Sociais, que estamos cada vez mais imersos em processos de desterritorialização, é demasiado simplista e, de certa forma, politicamente "imobilizante", pois imagina-se que, num mundo globalmente móvel, sem estabilidade, marcado pela imprevisibilidade e a fluidez das redes e pela virtualidade do ciberespaço, estamos quase todos à mercê dos poucos que efetivamente controlam estes fluxos e redes - ou, numa posição ainda mais extremada, nem mesmo eles podendo mais exercer, aí, algum tipo de controle.

Se o discurso da desterritorialização serve, antes de mais nada, àqueles que pregam a destruição de todo tipo de controle ou barreira espacial, ele claramente legitima a fluidez global dos circuitos do capital, especialmente do capital financeiro, num mundo em que o ideal a ser alcançado seria o enfraquecimento e, no limite, o desaparecimento do Estado, delegando todo poder às forças do mercado (ver, por exemplo, as teses de um "guru" da globalização como Ohmae [1990, 1996] sobre o "fim das fronteiras" e o "fim do Estado-nação").

Falar não simplesmente em desterritorialização mas em multiterritorialidade e territórios-rẹe, moldados no e pelo movimento, implica reconhecer a importância estratégica do espaço e do território na dinâmica transformadora da sociedade. Inspiramo-nos aqui no "sentido global de lugar" proposto por Doreen Massey (2000[1991]). Criticando as visões mais reacionárias que vêem o lugar apenas como um espaço estável, de fronteiras bem delimitadas e identidades bem definidas, um pouco como em alguns territórios-zona aqui comentados, a autora propõe uma visão "progressista" de lugar, "não fechado e defensivo", voltado para fora e adaptado a nossa era de compressão de espaçotempo.

Devemos, contudo, complexificar esta leitura, na medida em que nem só de "níveis" de multiterritorialidade vive a sociedade contemporânea. Velhas estratégias de "reclusão" territorial também se reconfiguram e se multiplicam, ao lado de movimentos reacionários de (relativo) fechamento territorial em torno de relações biunívocas entre território e identidades culturais essencializadas. $\mathrm{O}$ aumento da precarização econômica e territorial planetária também tem estimulado discursos neo-territorialistas em torno da segregação e mesmo do isolamento em nome da "segurança". Mas estes são temas que estamos aprofundando em um outro trabalho.

O território, como espaço dominado e/ou apropriado, manifesta hoje um sentido multi-escalar e multi-dimensional que só pode ser devidamente apreendido dentro de uma concepção de multiplicidade, tanto no sentido da convivência de "múltiplos" (tipos) de território quanto da construção efetiva da multiterritorialidade. Toda ação que se pretenda efetivamente transformadora, hoje, 
necessita, obrigatoriamente, encarar esta questão: ou se trabalha com a multiplicidade de nossas territorializações, ou não se alcançará a transformação que almejamos. Os movimentos contra o neoliberalismo e por uma outra globalização que o digam. Geograficamente falando, pensar multiterritorialmente significa pensar tanto em múltiplos poderes (ou "governanças") quanto em múltiplas identidades (em espaços culturalmente mais híbridos) e mesmo em múltiplas funções (a "multifuncionalidade" econômica) - em síntese, um debate complexo em prol da perspectiva maior de construção de uma outra sociedade, ao mesmo tempo mais universalmente igualitária e mais multiculturalmente reconhecedora das diferenças humanas.

Resumo: Este trabalho desdobra proposta anterior sobre a concepção de multiterritorialidade, a partir de um debate em torno dos conceitos de território, territorialidade e múltiplos territórios, aprofundando as várias manifestações das formas contemporâneas de multiterritorialidade.

Palavras-chave: Território - Territorialidade - Multiterritorialidade

\section{TERRITORY AND MULTITERRITORIALITY: A DEBATE.}

Abstract: This work aims to develop the conception of multiterritoriality, which we have already proposed, regarding always the debate of other concepts, as territory, territoriality and "multiple territories". In so doing, we stress the several manifestations of contemporary forms of multiterritoriality.

Keywords: Territory - Territoriality - Multiterritoriality

\section{BIBLIOGRAFIA}

AGAMBEN, G. 2002. Homo Sacer: O poder soberano e a vida nua I. Belo Horizonte: Ed. UFMG.

ANDERSON, B. 1989. Nação e Consciência Nacional. São Paulo: Ática.

ARENDT, H. 2004. Crises da República. São Paulo: Perspectiva.

ARRIGHI, G. 1996(1994). O longo século XX. Rio de Janeiro: Contraponto; São Paulo: EdUNESP.

BAREL, Y. 1986. Le social et ses territoires. In: Auriac, F. e Brunet, R. (orgs.) Espaces, Jeux et Enjeux. Paris: Fayard e Fondation Diderot.

BAUMAN, Z. 1999. Globalização: as conseqüências humanas. Rio de Janeiro: Jorge Zahar.

BAUMAN, Z. 2001(2000). Modernidade Liquida. Rio de Janeiro: Jorge Zahar. BOURDIEU, P. 1989. O Poder Simbólico. Lisboa e Rio de Janeiro: Difel e Bertrand Brasil.

CASTORIADIS, C. 1992. O Mundo Fragmentado: Encruzilhadas do Labirinto III. Rio de Janeiro: Paz e Terra.

DELEUZE, G. e GUATTARI, F. 1996 (1980). Mil Platôs: Capitalismo e 
Esquizofrenia. (vol. 2) Rio de Janeiro: Editora 34.

GIDDENS, A. 1991. As Conseqüências da Modernidade. São Paulo: EdUNESP. HAESBAERT, R. 1994. O mito da desterritorialização e as "regiões-rede". Anais do V Congresso Brasileiro de Geografia. Curitiba: AGB, pp. 206-214.

1997. Des-territorialização e Identidade: a rede "gaúcha" no Nordeste. Niterói: EdUFF.

2001a. Da desterritorialização à multiterritorialidade. Anais do IX Encontro Nacional da ANPUR. Vol. 3. Rio de Janeiro: ANPUR.

2001b. Le mythe de la déterritorialisation. Géographies et Cultures $n$. 40. Paris: L'Harmattan.

2002a. A multiterritorialidade do mundo e o exemplo da Al Qaeda. Terra Livre n. 7. São Paulo: Associação dos Geógrafos Brasileiros.

2002b. Fim dos territórios ou novas territorialidades? In: Lopes, L. e Bastos, L. (org.) Identidades: recortes multi e interdisciplinares. Campinas: Mercado de Letras.

2004a. O mito da desterritorialização: do "fim dos territórios" à multi-territorialidade. Rio de Janeiro: Bertrand Brasil.

2004b. Precarização, reclusão e "exclusão" territorial. Terra Livre n. 23.

HARVEY, D. 1992. A Condição Pós-Moderna. São Paulo: Loyola.

LACOSTE, Y. 1988 (1976). A Geografia isso serve, em primeiro lugar, para fazer a guerra. Campinas: Papirus.

LEFEBVRE, H. 1986(1974). La Production de l'Espace. Paris : Anthropos. LÉVY, P. 1996. O que é virtual. São Paulo : Ed. 34.

1999 (1997). Cibercultura. São Paulo : Ed. 34.

MASSEY, D. 2004. Filosofia e política da espacialidade. GEOgraphia n. 12.

2000 (1991) Um sentido global do lugar. In : Arantes, O. (org.) O espaço da diferença. Campinas : Papirus.

1993. Power-geometries and a progressive sense of place. In : Bird, J. et al. (eds.) Mapping the Futures : Local Cultures, Global Changes. Londres e Nova York : Routledge.

MORIN, E. e KERN, A. 1995. Terra Pátria. Porto Alegre : Sulina.

OHMAE, K. 1990. The borderless world : power and strategy in the interlinked economy. Londres : Collins.

1996. O fim do Estado Nação : a ascensão das economias regionais. Rio de Janeiro : Campus.

PINÇON, M. e PINÇON-CHARLOT, M. 2000. Sociologie de la Bourgeoisie. Paris : La Découverte.

2001. La dernière classe sociale : sur la piste des nantis. Le Monde Diplomatique set. 2001, pp. 24-25.

RAFFESTIN, C. 1993 (1980) Por uma Geografia do Poder. São Paulo : Ática. 
SACK, R. 1986. Human Territoriality : its theory and history. Cambridge : Cambridge University Press.

SANTOS, M. 1978. Por uma Geografia Nova. São Paulo : Hucitec.

SANTOS, M. et al. 2000. O papel ativo da Geografia : um manifesto. Florianópolis : XII Encontro Nacional de Geógrafos.

SOUZA, M. 1995. O território : sobre espaço e poder, autonomia e desenvolvimento. In : Castro, I. et al. (orgs.) Geografia : Conceitos e Temas. Rio de Janeiro : Bertrand Brasil.

ZAMBRANO, C. 2001. Territorios plurales, cambio sociopolítico y gobernabilidad cultural. Boletim Goiano de Geografia 21(1): 9-49. jan.-jul. 
